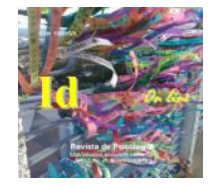

\title{
Concepções dos Profissionais de Saúde acerca da sexualidade do portador de Doença Mental
}

\author{
Ana Verônica de Alencar ${ }^{1}$, Maria do Carmo Eulálio ${ }^{2}$, Joelma dos Santos Barbosa Linhares Garcia ${ }^{3}$;
}

\begin{abstract}
Resumo: A sexualidade é um fenômeno intrínseco aos seres humanos. Às pessoas portadoras de doença mental não é diferente Entretanto, pela doença ou pelo estigma; esta dimensão pode receber conotações diferenciadas. Tivemos por objetivo, identificar e analisar as concepções da sexualidade de portadores de doença mental pelos profissionais de saúde que trabalham com os mesmos, destacando a importância que a concepção a qual o profissional possui, norteia a sua prática profissional e consequentemente influencia na maneira de lidar com esse sujeito, favorecendo ou não a recuperação. Os dados foram coletados através do questionário, da técnica de associação livre de palavras, com o estímulo indutor: "sexualidade do doente mental", juntamente com uma entrevista semi-diretiva. Participaram do estudo 20 profissionais, funcionários de uma instituição psiquiátrica da cidade de Campina Grande, PB. Realizamos análise combinada da freqüência e ordem média de evocações das palavras e análise de conteúdo categorial temática. Os resultados mostram que os profissionais encaram a sexualidade do doente mental como algo que está diretamente associada com a sua enfermidade encontrando-se, portanto fora dos padrões de normalidade, visto que a categoria de maior frequiência na associação livre foi o excesso, evocação essa que está intimamente ligada à negação da sexualidade do doente mental. Dado que foi muito recorrente também nas entrevistas. Logo os participantes acabam por lidar com essa sexualidade excessiva e desviante negando-a, seja através da repressão, da prática sexual em si ou coibindo até a verbalização do desejo sexual do doente mental. Assim, negar a expressão da sexualidade deste sujeito nada mais é que enxergá-lo de maneira preconceituosa e errante. A percepção dos profissionais da saúde a respeito da sexualidade do doente mental é expressa através da negação, da associação aos desvios, transgressões e doença. Evidencia-se, portanto, a necessidade de um olhar atento para as questões que envolvem a sexualidade deste indivíduo que precisa ser assistido em todas as suas dimensões: física, afetiva e social.
\end{abstract}

Palavras Chaves: Doente mental, sexualidade, profissionais de saúde mental.

\section{Conceptions of Health Professionals about the Sexuality of the Patient with Mental Illness}

\begin{abstract}
Sexuality is a phenomenon intrinsic to humans. To people with mental illness is no different, however, by disease or stigma, this dimension may receive different connotations. Our aim was to identify and analyze the conceptions of sexuality of patients with mental health professionals who work with them, highlighting the importance of the conception which has the professional, guides their professional practice and consequently influence in way of handling with this guy, whether or not promoting the recovery. Data were collected through the questionnaire, the technique of free association of words with the inducing stimulus: "sexuality of the mentally ill", along with a semi-directive interview.Participants were 20 professional employees in a psychiatric institution in the city of Campina Grande, PB. We conducted a combined analysis of the frequency and average order evocations of words and content analysis categories and themes. The results show that professionals face sexuality of the mentally ill as something which is directly associated with their illness lying therefore outside the normal range, whereas the category of highest frequency in free association was over, evocation that this is intimately linked to the denial of sexuality of the mentally ill. Given that it was also very
\end{abstract}

\footnotetext{
1 Graduação em Psicologia pela Universidade Estadual da Paraíba, Brasil. Professora da Faculdade Kurios - Núcleo de Pós-Graduação, Pesquisa e Extensão, Brasil

2 Doutora em Psicopatologia clínica na Université Paul Valéry;

3 Graduação em Ciências econômicas pela Universidade Regional do Cariri - URC A; Especialização em Metodologia do Ensino Fundamental e Médio pela Universidade Estadual Vale do Acaraú, Brasil e Mestranda em Ciências da Educação pela Universidad San Carlos - Paraguai. E-mail: jsblinharesgarcia@ hotmail.com
} 
recurrent in the interviews. Soon the participants end up dealing with this excessive and deviant sexuality by denying it, either through repression, of sexual practice itself or disparage until verbalization of sexual desire of the mentally ill. Thus to deny the sexuality of this subject is nothing more than seeing it in a prejudicial manner and errant. The perception of health professionals about the sexuality of the mentally ill is expressed through denial, the deviations of the association, transgressions and disease. It is evident, therefore, the need for a closer look at the issues surrounding sexuality of that needs to be seen in all its dimensions: physical, emotional and social.

Key Words : Mental Illness, sexuality, mental health professionals .

\section{Introdução}

Cada profissional de saúde utiliza um modo particular para se posicionar em relação ao doente mental e, assim, circunscreve uma percepção da sexualidade do mesmo, na imprecisão dos sinônimos atribuídos. Seu posicionamento, enquanto opinião revela seu comportamento e seus juízos de valor, direcionando o desempenho desse papel profissional que, à primeira vista, tende a certa neutralidade sobre as manifestações da sexualidade do doente mental.

O profissional é solicitado, continuamente, a emitir opiniões e transmitir informações, no interior da instituição a que pertence, seja aos pacientes, seja aos familiares e pessoas da comunidade em geral. O profissional da saúde estabelece uma maneira de inferir sobre a questão que geralmente consiste na negação da sexualidade do portador de doença mental. A tendência à homogeneidade, na atitude deste, tem por base a forma como a sexualidade é abordada no contexto institucional, sem eliminar a interferência da maneira como cada indivíduo vê e interpreta a questão.

Este trabalho teve por objetivo identificar e analisar as concepções da sexualidade de portadores de doença mental por profissionais de saúde mental da cidade de Campina Grande.

Buscamos investigar se esses profissionais compartilham de uma visão tecnicista e fragmentada do doente mental ou se, pelo contrário, existe um olhar mais humanizado. È importante destacar que a concepção que o profissional possui, norteia a sua prática profissional e consequentemente, influencia na maneira de lidar com esse sujeito, favorecendo ou não a recuperação.

\section{O discurso sobre a sexualidade na literatura}

A sexualidade humana está associada, a um núcleo de bem-estar que inclui: primeiramente, gênero (conjunto de valores, atitudes, papéis, práticas ou características culturais baseadas no sexo biológico),segundo, identidade sexual e de gênero (como a pessoa se identifica), terceiro, orientação do desejo sexual, erotismo, vínculo emocional, atividades e práticas sexuais, relações sexuais sem 
risco e comportamento sexual responsável. Portanto a sexualidade é conseqüência da integração de fatores biológicos, psicológicos, sócio-econômicos, culturais, étnicos e espirituais (TONIETTE, 2006 apud HELLMANN,2006).

O termo sexualidade surgiu no século XIX, marcando algo diferente do que apenas um remanejamento de vocabulário. O uso desta expressão é estabelecida em relação a outros fenômenos, como o desenvolvimento de campos de conhecimento diversos; a instauração de um conjunto de regras e de normas apoiadas em instituições religiosas, judiciárias, pedagógicas e médicas; modificando no modo pelo qual os indivíduos são levados a dar sentido e valor a sua conduta, desejos, prazeres, sentimento, sensações e sonhos (FOUCAULT, 1985). Para o autor, não se deve conceber a sexualidade

como uma espécie de dado da natureza que o poder é tentado a pôr em xeque, ou como um domínio obscuro que o saber tentaria, pouco a pouco, desvelar. A sexualidade é o nome que se pode dar a um dispositivo histórico: não a uma realidade subterrânea que se apreende com dificuldade, mas à grande rede da superfície em que a estimulação dos corpos, a intensificação dos prazeres, a incitação ao discurso, à concepção do conhecimento, o reforço dos controles e das resistências, encadeiam-se uns aos outros, segundo algumas grandes estratégias de saber e de poder. (FOUCAULT, 1985, p.100).

Para Foucault (1985 apud GIAMI, 2005) o termo "sexualidade" tem um significado comum para referir-se às práticas, relações e aspectos discursivos sexuais, e ao mesmo tempo para delinear o "dispositivo da sexualidade" (considera globalmente a sexualidade como uma dimensão central da relação com a verdade, relação que se opera através dos dispositivos de saber e de poder), isto é, daquilo que funcionou no século XIX como propriedade da verdade específica deve ser feita, antes de tudo, do enfoque de uma "história dos discursos". Assim Foucault, escreve:

Vemos claramente: é o dispositivo de sexualidade que, em suas diferentes estratégias, instaura essa idéia 'do sexo' e o faz aparecer, sob as quatro grandes formas - da histeria, do onanismo, do fetichismo e do coito interrompido - como sendo submetido ao jogo do todo e da parte, do princípio e da falta, da ausência e da presença, do excesso e da deficiência, da função e do instinto, da finalidade e do sentido, do real e do prazer. Assim, formou-se pouco a pouco a armação de uma teoria geral do sexo (FOUCAULT, 1985).

Conforme Foucault (1985), a partir do século XVII, formou-se uma aparelhagem para a produção de discursos sobre o sexo, a qual, baseada na técnica da confissão, possibilitou a constituição do sexo como objeto de verdade. A confissão difundiu amplamente seus efeitos - entre outros, na pedagogia - e, através de dispositivos que passaram a produzir discursos verdadeiros sobre o sexo, pôde aparecer algo como a sexualidade, enquanto verdade do sexo e de seus prazeres. A sexualidade, 
portanto, funciona como uma economia dos discursos. E no jogo de dizer a verdade sobre o sexo, constitui-se um saber, saber este que nos constitui como sujeitos.

Jacquart; Thomasset (1985 apud GIAMMI 2005) dizem que Foucault situa a gênese da sexualidade numa aplicação progressiva da confissão e desvelamento, e não como uma análise da medicalização (as práticas médicas e os valores médicos irradiariam o mundo social, tentando apropriar-se do discurso sobre a sexualidade) da sexualidade como uma extensão das medicinas sexuais que se ampliaram ao longo da história ocidental. O exercício da confissão se inscreve numa história que Foucault retraça e que é pontuada por uma modificação de conteúdo da confissão e penitência em confissão e desvelamento. Assim, entre os séculos XII e XVI, a confissão é inteiramente emoldurada pelos preceitos jurídicos:

Ora, essa filtragem das obrigações ou das infrações sexuais concerne quase
inteiramente, quase exclusivamente, ao que poderíamos chamar de aspecto relacional da
sexualidade [...] Não é mais o aspecto relacional, mas o próprio corpo do penitente, são
seus gestos, seus sentidos, seus prazeres, seus pensamentos, seus desejos, a intensidade
e a natureza do que ele próprio sente [...]. O novo exame vai ser um percurso meticuloso
do corpo, uma espécie de anatomia da volúpia. [...] Portanto a confissão não se
desenrolará mais de acordo com essa ordem de importância, na infração das leis da
relação, mas deverá seguir uma espécie de cartografia pecaminosa do corpo
(FOUCAULT, 1985).

Foucault (1975) assinala uma outra dimensão como indispensável dos saberes sobre a sexualidade: a psiquiatria. Ele coloca a emergência da problematização psiquiátrica e sexológica da sexualidade em 1844, num movimento mais vasto e global que vai unir o instinto sexual natural, opondo-o a seus desvios. Tal abordagem da sexualidade se diferencia pela identificação de um instinto sexual que constitui o conjunto do comportamento, tanto na masturbação como no comportamento sexual reprodutivo. Trata-se de uma teoria da sexualidade segundo a qual a sexualidade humana se implanta por seus mecanismos, por suas formas gerais, na história natural de uma sexualidade que se pode remontar até as plantas. A declaração de um instinto sexual é a manifestação, não se poderia dizer psíquica, mas meramente dinâmica, do funcionamento dos órgãos sexuais. Do próprio modo que existe uma dinâmica da fome que corresponde aos aparelhos da nutrição, uma impressão, um sentimento, vai haver um instinto sexual, que corresponde ao funcionamento dos órgãos sexuais. É uma naturalização muito marcada da sexualidade humana e, do mesmo modo, seu princípio de generalização. Por esse instinto, a cópula (ou seja, o ato sexual relacional heterossexual) é igualmente natural e normal. Mas, além disso, o conjunto de "aberrações" do funcionamento normal do instinto sexual é devido a imaginação mórbida, ou seja, a fantasia: É ela que cria antecipadamente o desejo, ou que, melhor dizendo, iluminada por desejos prematuros, vai buscar os meios adjuntos, derivados, substitutivos de se satisfazer. 
Para o referido autor, a análise dessa busca da verdade sobre o sexo, da formação de um certo tipo de saber sobre o sexo, deve ser feita sob o viés do poder, não um poder que funcione pelo direito, não pela lei, mas pela técnica;não pelo castigo, mas pela normalização, pelo controle. O poder é onipresente porque se produz a cada instante, em todos os pontos, em toda relação: ele está em toda parte não porque englobe tudo, mas porque provém de todos os lugares. A nova tecnologia do sexo, que nasce no século XIX, escapa à instituição eclesiástica e se desenvolve ao longo de três eixos: o da pedagogia, o da medicina e o da demografia. O sexo passa a ser negócio de Estado e, para que ele seja administrado, todo o corpo social e quase cada um de seus indivíduos são convocados a posicionaremse em vigilância.

Altman (2001) afirma à importância da sexualidade como

[...] foco de disputa política deve-se ao fato de ele se encontrar na articulação entre os dois eixos ao longo dos quais se desenvolveu toda a tecnologia da vida política: o sexo faz parte das disciplinas do corpo - permitindo o exercício de um micropoder - e pertence à regulação das populações. Assim, a sexualidade foi esmiuçada e tornou-se chave da individualidade, dando acesso à vida do corpo e à vida da espécie, permitindo o exercício de um biopoder sobre a população. (p. 577-578).

Foucault, (1997 apud ALTMAN, 2001, p.2) diz que o discurso sobre a sexualidade é o que há de mais íntimo nos indivíduos e aquilo que os reúne globalmente como espécie humana. Está inserida entre as "disciplinas do corpo" e participa da "regulação das populações". A sexualidade é um "negócio de Estado", tema de interesse público, pois a conduta sexual da população diz respeito à saúde pública, à natalidade, à vitalidade das descendências e da espécie, o que, por sua vez, está relacionado à produção de riquezas, à capacidade de trabalho, ao povoamento e à força de uma sociedade. Ele afirma também que esse tipo de poder foi indispensável no processo de afirmação do capitalismo, que pôde desenvolver-se "à custa da inserção controlada dos corpos no aparelho de produção e por meio de um ajustamento dos fenômenos de população aos processos econômicos".

Segundo Altman (2001, p.576)

Além de foco de disputa política, a sexualidade possibilita vigilâncias infinitesimais, controles constantes, ordenações espaciais meticulosas, exames médicos ou psicológicos infinitos. A sexualidade, portanto, é uma via de acesso tanto a aspectos privados quando públicos. Ela suscita mecanismos heterogêneos de controle que se complementam, instituindo o indivíduo e a população como objetos de poder e saber.

O discurso sobre a sexualidade, enquanto mecanismo heterogêneo de controle escoa-se também através da concepção religiosa seu caráter de "objeto da verdade" Costa, (1986 apud CANO; FERRIANI e GOMES, 2000) diz que a sexualidade vem carregada de tabus que afetam a maneira de se encará-la, e o primeiro deles refere-se ao "pecado" de Adão e Eva, a partir do qual, tudo o que diz 
respeito ao relacionamento sexual está ligado a um sentimento "de vergonha". Outros tabus são os de que os anjos são assexuados e, portanto puros, e o diabo representa a sexualidade vivida em promiscuidade; todos eles atestam uma atitude desfavorável da igreja com relação ao sexo e ao prazer.

Cabral (1995 apud CANO; FERRIANI e GOMES, 2000), acrescenta uma outra idéia transmitida pela doutrina cristã no ocidente, que é a dualidade entre corpo e alma, na qual a alma é mais importante que o corpo, pois a mesma recebeu de Deus a existência e a imortalidade. Ao longo da história ocidental, tem-se favorecido uma educação sexual que valoriza a alma em detrimento do corpo. Esta tem sido uma forma de os homens viverem a sexualidade de maneira reprimida.

Segundo Costa (1986 apud CANO; FERRIANI e GOMES, 2000) principalmente a partir do século XVI, quando se inicia o processo de modernização da sociedade e a ascensão da burguesia, as normas, os valores cristãos e as necessidades do Estado foram enquadrando a sexualidade, aliando as influências da Igreja e dos moralistas no controle da vida social.

Cano; Ferriani e Gomes, (2000) acrescentam que a sexualidade foi fortemente influenciada pelas idéias cristãs, culturais, políticas e econômicas, nas quais a iniciação sexual da mulher deveria se dar no casamento e ter fins procriativos, enquanto ao homem eram permitidas a prática sexual e a busca do prazer fora dos limites do matrimônio. Eles concluem dizendo que nessa época (a partir do século XVI), o poder da ciência e da tecnologia vem ditando novas regras, estabelecendo permissões e proibições para os relacionamentos sexuais.

Foucault (1985) diz ainda que nas sociedades modernas as repressões sobre o sexo não são formas essenciais de poder. Proibições fazem parte de uma economia discursiva mais ampla que visa à constituição de uma aparelhagem para produzir discursos sobre o sexo, os quais passaram a ser essenciais para o funcionamento de mecanismos de poder. Cumpre falar do sexo como de uma coisa que não se deve simplesmente condenar ou tolerar, mas gerir, inserir em sistemas de utilidade, regular para o bem de todos, fazer funcionar segundo um padrão ótimo. O sexo não se julga apenas, administra-se.

Souza (2001) diz que a sexualidade tem sido colocada como central à nossa existência. Ela observa que é possível depreender junto ao Referencial Curricular Nacional para a Educação Infantil, a grande importância atribuída à sexualidade no desenvolvimento e na vida psíquica das pessoas, pois independentemente da potencialidade reprodutora, relaciona-se com o prazer, necessidade fundamental dos seres humanos.

Esse discurso naturalizante e universal em torno da sexualidade têm produzido poderosos efeitos de verdade.

No entanto, Jeffrey Weeks (apud SOUZA 2001) observa que a sexualidade, embora tendo como suporte um corpo biológico, deve ser vista como uma construção social, uma invenção histórica, pois o valor que lhe é atribuído é modelado em situações sociais concretas. A sexualidade é tida como 
uma verdade definitiva sobre nós mesmos e sobre nossos corpos, mas está além da dimensão individual, ela nos revela algo mais sobre a verdade da nossa cultura.

Os mecanismos de controle social passam, entre outras coisas, pelas estratégias de disciplina dos corpos e das mentes, concebidas e implantadas - ainda que jamais de forma absoluta e completa - a partir da disseminação de certos valores morais referentes, à sexualidade e seus desvios.

Portanto segundo Foucault (1980 apud ENGEL, 1999, p.21)

[...] os comportamentos sexuais considerados anormais são identificados como doença. Essa identificação ocupa um lugar cada vez mais preeminente na etiologia e na sintomatologia das doenças mentais, ganhando maior abrangência e profundidade no pensamento e na prática psiquiátricos de fins do século XIX, momento que é marcado, de um lado, pelo surgimento e consolidação da psiquiatria propriamente dita e, por outro, pela difusão dos princípios norteadores da degenerescência e do organicismo.

Logo se percebe a insistência de médicos e psiquiatras em buscar, no comportamento sexual dos pacientes observados, a presença de desvios que eram imediatamente relacionados às causas, aos efeitos e/ou aos sintomas da doença que queriam diagnosticar, existindo uma profunda proximidade entre a loucura e as anomalias do instinto sexual, definidas como a diminuição ou ausência, o exagero (veemência ou insaciabilidade) e a perversão (ou aberração) do desejo sexual. O excesso, a falta e/ou a perversão instituíam, portanto, os elementos básicos que definiam os limites vastos e incertos das anomalias sexuais. Observa-se, no entanto, que os alienistas trataram de definir também, de um modo até mais intenso e evidente, os limites da normalidade das práticas sexuais, circunscritas, simultaneamente, ao prazer moderado e à finalidade reprodutora.

As anomalias e/ou perversões da sexualidade ajudariam, qualitativas ou quantitativas, a construir e solidificar a noção psiquiátrica de doença mental, conferindo-lhe limites extremamente amplos e difusos (ENGEL, 1999).

Esta pesquisa foi realizada em um hospital psiquiátrico da cidade de Campina Grande-PB, com profissionais da saúde que lidam diretamente com portadores de distúrbios psiquiátricos.

A amostra foi composta por acessibilidade e a quantidade de participantes obedeceu ao critério de saturação. O ponto de saturação é, segundo Gaskell (2002), um momento em que o pesquisador percebe que não surgem mais novos conteúdos relevantes para a pesquisa. A amostragem por acessibilidade constitui o menos rigoroso de todos os tipos de amostragem, por isto mesmo é destituída de qualquer rigor estatístico. O pesquisador seleciona os elementos para compor a amostra. Aplica-se este tipo de amostragem em estudos exploratórios ou qualitativos onde não é requerido elevado nível de precisão (PRÓ PESQUISA, 2006).

Os instrumentos utilizados foram: a associação livre de palavras, o questionário e a entrevista semi diretiva. A respeito da associação livre de palavras Freud (1892 apud SANTO, 2002) diz que, 
http://idonline.emnuvens.com.br/id

ISSN on-line: 1981-1179

esta técnica consiste em, o paciente falar livremente tudo que lhe vier a cabeça, sem censura por mais estranho e absurdo que lhe pareça, conseguindo assim decifrar a cadeia causal inconsciente que produz o sintoma através da análise de discurso do paciente. O questionário que terá fins de captação de dados sócio-demográficos, que segundo Parasuraman (1991 apud CHAGAS, 2000) é tão somente um conjunto de questões, feito para gerar os dados necessários para se atingir os objetivos de pesquisa. Embora o mesmo autor afirme que nem todos os projetos de pesquisa utilizam essa forma de instrumento de coleta de dados, o questionário é muito importante na pesquisa científica, especialmente nas ciências sociais. Sobre a entrevista Colognese e Mélo (1998 apud GRINGS; MALLMANN, 2000) diz que é um instrumento no qual o entrevistador tem por objetivo obter informações do entrevistado relacionadas a um objetivo específico. Nesse estudo será utilizada a entrevista semi-estruturada, que é caracterizada pela formulação da maioria das perguntas previstas com antecedência e sua localização é provisoriamente determinada. Na entrevista semi-estruturada o entrevistador tem uma participação ativa, apesar de observar um roteiro, ele pode fazer perguntas adicionais para esclarecer questões para melhor compreender o contexto.

Para análise da associação livre de palavras e do questionário, lançamos mão dos recursos da estatística descritiva que segundo (GIL, 2002) as pesquisas descritivas têm como objetivo primordial a descrição das características de determinada população ou fenômeno ou, então, o estabelecimento de relações entre variáveis. Tendo como uma de suas características mais significativas à utilização de técnicas padronizadas de coleta de dados, tais como o questionário e a observação sistemática. Para a entrevista semi-diretivas, utilizamos a análise de conteúdo categorial temática proposta por Bardin (1997), através da qual é possível ir além dos significados imediatos, realizando uma análise mais atenta da fala do participante, realizando uma categorização e, então, interpretação através de uma técnica de inferência.

Com relação ás questões éticas, este estudo cumpriu o que preceitua a Resolução 196/96 sobre estudos envolvendo seres humanos.

\section{Resultados e Discussão}

Participaram da pesquisa 20 profissionais, funcionários de um hospital psiquiátrico de ambos os sexos, 10 de nível médio e 10 de nível superior: 3 assistentes sociais, 2 enfermeiras, 2 médicos, 2 psicólogas, 1 nutricionista, 4 auxiliares de enfermagem e 6 técnicos de enfermagem. Os participantes da nossa pesquisa tinham em média 38 anos variando a idade de 20 a 51 anos, a maioria casada (60\%); dos participantes,75\%(15) declararam ter religião, dentre estes 7 afirmaram ser da religião católica, 7 são evangélicos e 1 espírita. Um fato que chamou a atenção foi que $25 \%$ (5) do total dos entrevistados 
afirmaram não possuir nenhuma religião, mas a própria instituição desenvolve atividades de cunho religioso, até mesmo como forma de educação sexual para os doentes mentais, esse dado será melhor desenvolvido no decorrer da apresentação dos dados da entrevista.

A figura em seguida ilustra a distribuição da religião entre os participantes:

\section{Gráfico 1: Caracterização da Religião declarada pelos participantes}

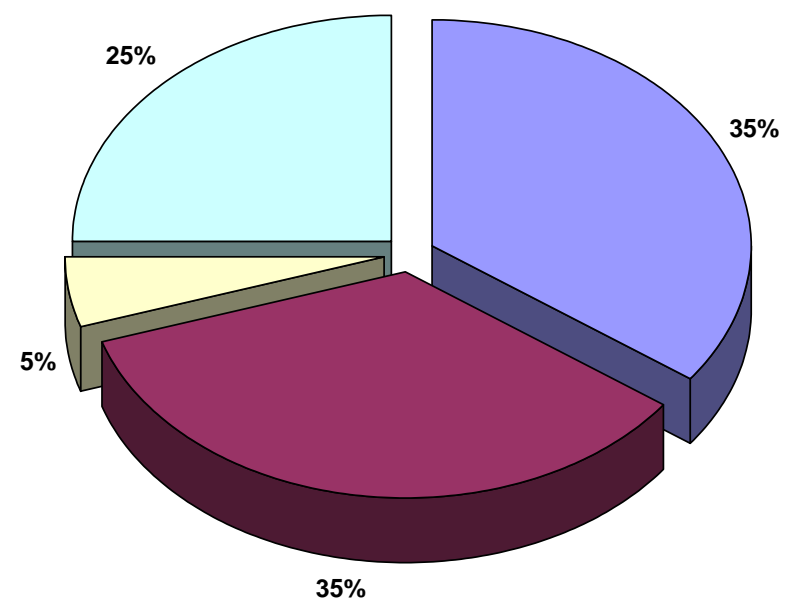

Entre os profissionais de nível médio (10), a renda familiar, predominantemente, é de 1 a 3 salários mínimos, por outro lado, entre os profissionais de nível superior a renda variou bastante: de 1 a 3 salários mínimos até 9 salários.

\section{Gráfico 2: Distribuição da renda familiar mensal dos participantes da pesquisa}

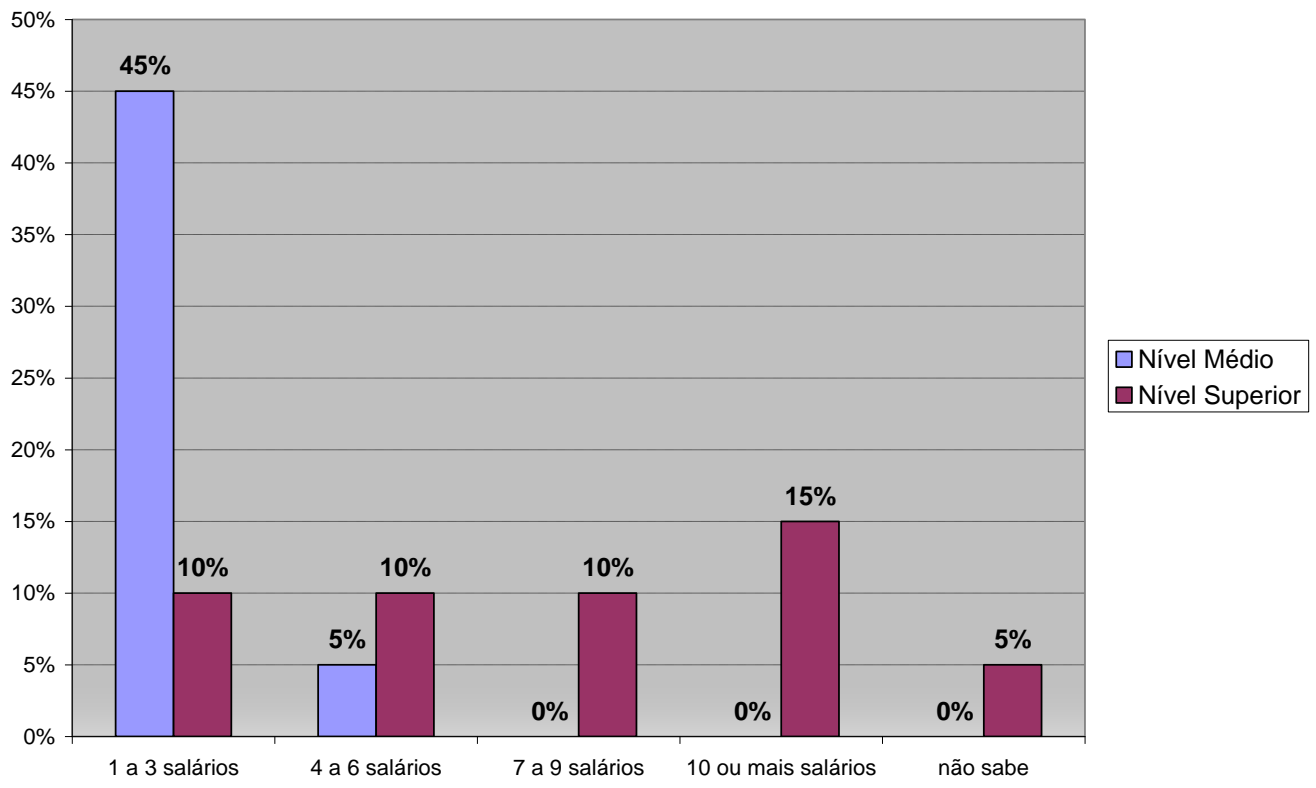


O tempo que os participantes declararam trabalhar com portadores de doença mental variou de 1 a 30 anos, atingindo a média de 12 anos.

Quanto ao motivo que fez esses profissionais trabalharem com o portador de doença mental foi associado ao amor, a tradição familiar, a necessidade financeira e a falta de opção, entretanto, dentre estas respostas a que foi mais recorrente foi o amor ao paciente que surgiu na fala de $75 \%$ (15) dos participantes.

Em relação à possibilidade do doente mental poder levar uma vida normal, os profissionais assim se posicionaram: $10 \%$ (2) declararam sim, justificando que como ser humano o portador de doença mental tem as mesmas necessidades de qualquer sujeito, $10 \%$ (2) declararam não, pois eles não possuem controle sobre si, assim vão depender sempre de alguém para assisti-los. A grande maioria $80 \%$ (16) declaram sim, mas as justificativas eram pautadas em condicionantes: ora pela gravidade da doença, ora pelo posicionamento da sociedade frente ao doente que foi internado em uma instituição psiquiátrica.

Quanto à motivação para esses profissionais permanecerem trabalhando na instituição psiquiátrica, a justificativa da motivação inicial em trabalhar nessa área foi assim descrita: o amor ao paciente $(75 \%)$ e o restante $(25 \%)$ necessidade financeira ou falta de opção, asseguram que permanecem com os pacientes por ter estabelecido um vínculo afetivo.

\section{A Associação Livre de Palavras}

Utilizamos como estímulo indutor a expressão "sexualidade do doente mental" e obtivemos um total de sessenta evocações (apêndice D). Estas foram agrupadas (maiores detalhes no apêndice E) de acordo com a aproximação léxica e semântica, resultando nas seguintes categorias:

Quadro 1: Distribuição das Categorias, freqüência e ordem das evocações

\begin{tabular}{|l|c|c|c|c|}
\hline \multicolumn{1}{|c|}{ CATEGORIA } & EVOC 1 & EVOC 2 & EVOC 3 & F \\
\hline EXCESSO & 5 & 4 & 2 & 11 \\
\hline COMUM & 2 & 1 & 2 & 5 \\
\hline NECESSIDADE & 2 & 1 & 2 & 5 \\
\hline SIGNIFICATIVO & 1 & 1 & 3 & 5 \\
\hline CUIDADO & 2 & 1 & 1 & 4 \\
\hline DIFÍCIL & 1 & 2 & 1 & 4 \\
\hline PRECONCEITO & 2 & 1 & 0 & 3 \\
\hline ALUCINAÇÃO & 1 & 2 & 0 & 3 \\
\hline REPRESSÃO & 1 & 1 & 1 & 3 \\
\hline Continua...... & - & - & - & - \\
\hline
\end{tabular}

Id en line Revista de Psicologia. Ano 7, No. 21, Novembroo/2013 - ISSN 1981-1179.

Edição eletrônica em http://idonline.emnuvens.com.br/id 
http://idonline.emnuvens.com.br/id

ISSN on-line: 1981-1179

\begin{tabular}{|l|c|c|c|c|}
\hline INCOMPREENS ̃̃O & 0 & 2 & 1 & 3 \\
\hline FALTA & 1 & 0 & 1 & 2 \\
\hline SEXO OPOSTO & 0 & 2 & 0 & 2 \\
\hline Total geral & 18 & 18 & 14 & 50 \\
\hline
\end{tabular}

Número de categorias 12

Total de evocações 60

Total de evocações consideradas 50

A partir desses dados, foi possível construir um esquema na figura ilustrativa sobre a distribuição das categorias elaboradas a partir do estímulo fornecido.

Figura 1: Distribuição das categorias da associação livre de palavras para a expressão-estímulo: "sexualidade do doente mental"

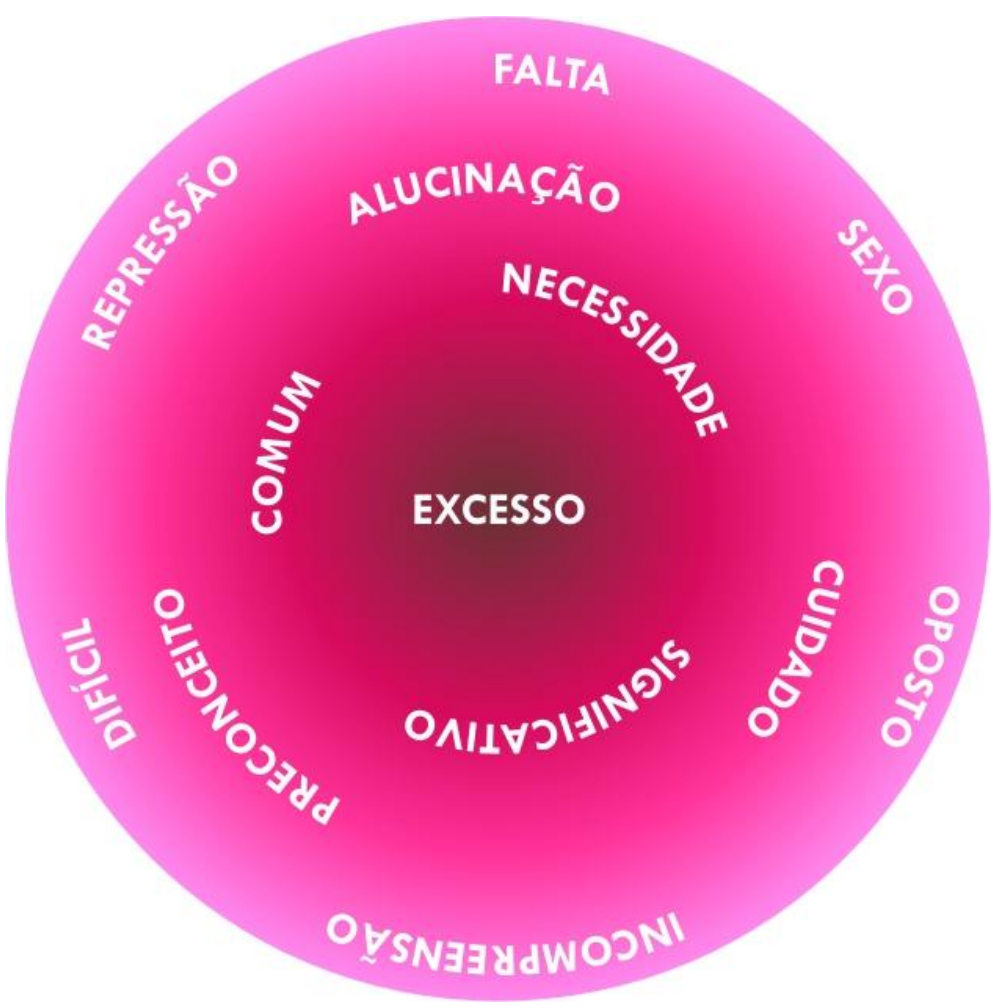

Como podemos observar, a categoria que obteve o maior número de evocações e encontra-se no centro da ilustração, foi a categoria excesso. Este fato revela que a sexualidade dos doentes mentais é encarada pelos profissionais da saúde mental como algo diretamente associado com sua enfermidade, e o seu caráter de transbordar, seria o mais lembrado pelos entrevistados, atribuindo-lhe um status de "fora dos padrões de normalidade". 
Algumas categorias estão afastadas do centro da ilustração, entretanto mantêm uma relação muito próxima com ele. O excesso é a expressão de uma sexualidade, vista pela maioria dos profissionais entrevistados como patológica, por isso a categoria alucinação que traz forte associação com preconceito e incompreensão.

Outra categoria que nos chamou atenção foi repressão. Embora os profissionais refiram-se a sexualidade do doente mental como reprimida eles não declaram assumir o papel de agentes repressores, como veremos na análise das entrevistas.

\section{As concepções sobre a sexualidade do doente mental}

Os discursos dos entrevistados acerca da sexualidade do doente mental foram lidos exaustivamente, agrupados e categorizados nos seguintes temas:

- $\quad \mathrm{O}$ ato sexual como única expressão da sexualidade;

- Verbalização intensa do desejo de praticar o ato sexual manifestada pelo doente mental

- A Masturbação como uma expressão da sexualidade do doente mental;

- Um aumento significativo da libido (erotização exagerada) quando o paciente entra em surto (crise);

- Prática sexual encarada como sendo apenas um ato sexual e heterossexual;

- O surto em forma de delírio, como justificativo para a manifestação da sexualidade do doente mental;

- A negação da sexualidade do doente mental

\section{O ato sexual como única expressão da sexualidade}

Ao falarmos de sexualidade, com os profissionais entrevistados percebemos que a percepção destes a respeito dessa temática está intimamente ligada ao ato sexual em si, encarando a sexualidade como uma necessidade física do ser humano, como podemos observar em algumas falas o que esses profissionais entendem sobre sexualidade: 
Entendo que é uma necessidade fisiológica de todo ser humano, alias de todo animal, é uma necessidade fisiológica... o corpo pede, a mente pede $\left(\mathrm{E} 4, \mathrm{PNS}^{3}\right)$.

Sexualidade quando a gente vê falar, agente pensa logo numa relação a dois, ou seja, a dois ou duas pessoas do sexo oposto (E16, PNS).

Pode-se perceber que as concepções da maioria dos entrevistados sobre a sexualidade, estão mais calcadas numa sexualidade ligada diretamente ao sexo. Estas concepções estão bem distantes da definição de sexualidade de Ballone (2006) que, segundo ele, não é um instrumento ligado unicamente ao ato sexual, e que deve ser entendida como: expressão da afetividade, capacidade de estar em contato consigo e com o outro; como construção da auto-estima e do bem-estar.

Assim essa categoria vem a subsidiar as posteriores impressões dos profissionais da área de saúde a respeito da sexualidade do doente mental.

\section{Verbalização intensa do desejo de praticar o ato sexual manifestada pelo doente mental}

O portador de doença mental utiliza-se da verbalização exacerbada como uma das formas predominantes de expressão da sua sexualidade, já que a prática sexual é em todas as suas instâncias negligenciada pela instituição.

Segundo Gejer (2006) o deficiente mental, como qualquer outro sujeito, tem necessidade de expressar seus sentimentos de maneira particular e intransferível.

Assim segundo a maioria dos profissionais entrevistados as falas bem recorrentes, e excessiva, utilizadas pelos pacientes, estão associadas ao ato sexual, como quando estes falam nas esposas, desejando o ato sexual e/ou querem arrumar namoradas, bem como fantasias eróticas homossexuais.

[...] aqueles que têm libido mais alta, são aquele que não param de falar nas esposas... vivem dizendo que vão arrumar namoradas [...] (E2, PNM).

[...] as mulheres falam muito em sexo, falam muito que precisam de homens, que faz muito tempo que não tem homem, elas falam que gostam, é esse tipo de coisa [...]" (E13, PNM).

A percepção destes profissionais acerca da verbalização erótica do doente mental, parece está associada como mais uma forma de manifestação de um estado delirante (surto) do mesmo.

\footnotetext{
${ }^{3}$ Entenda-se: primeiro código (E4) - número de identificação dos entrevistados; segundo código (PNM - Profissional de Nível Médio, PNS - Profissional de Nível Superior) - nível de escolaridade do entrevistado. 


\section{A masturbação como uma expressão da sexualidade do doente mental}

Além da verbalização erótica, por parte do portador de doença mental, uma outra forma freqüente de manifestar a sua sexualidade é através da prática da masturbação, ato este que é percebido pela maioria dos profissionais como prática comum, entre os internos psiquiátricos como pode ser observado a seguir:

[...] a libido deles é bem aguçada mesmo. E não conseguem controlar, né... Se masturbam... Tanto as mulheres como os homens estão sempre se masturbando [...] (E6, PNM).

[...] eles ficam pensando na mulher, estão fora de casa, passam muito tempo aqui. Às vezes um mês um mês e pouco, dois meses. Aí ficam nessa dependência... Com vontade de fazer, de se masturbar [...] quando eles tão nessa fase agente medica. Agente fala com o médico e ele passa uma medicação e vai administrando. Ou então ele muda a medicação justamente para que ele não entre assim nessa dependência (E18, PNM).

Freud (1923 apud ARAÚJO, 2002) coloca o narcisismo como uma etapa entre o auto-erotismo (masturbação) e o amor objetal abordando a possibilidade que a libido tem de reinvestir o ego desinvestindo o objeto. Objeto esse da pulsão, que produz prazer de órgão também passando a ser objeto da atividade narcísica. Assim as atividades das zonas erógenas podem passar a serem utilizadas independentemente do prazer ou desprazer que causem, simplesmente para satisfazer a superioridade do ego, verificadas assim na masturbação.

Segundo Miranda; Furegato, (2004) a respeito do auto-erotismo diz que essa expressão da sexualidade é vigiada e controlada pelos profissionais por meio da observação contínua e se possível sob contenção no banho individual, bem como, o uso da medicação, pela possibilidade da masturbação, como controle sobre o corpo do doente mental.

\section{Um aumento significativo da libido (erotização exagerada) quando o paciente entra em surto (crise)}

Os entrevistados associam a exacerbação da libido, do paciente portador de doença mental, ao momento de delírio. Segundo tais profissionais a verbalização do desejo sexual bem como as práticas sexuais é evidenciada de forma excessiva quando o indivíduo está em surto, o que se pode perceber, nas entrevistas, assim como, na associação livre de palavras, que este excesso está intimamente ligado a patologia deste indivíduo. 
[...] elas na crise muitas, não estou dizendo todas, mas uma boa parte, uma terça parte, elas afloram sexualidade, elas só falam nisso é só pensam que querem fazer que querem assediar[...](E11, PNM).

[...] Masturbação concerteza, isso é a coisa mais normal do mundo você encontrar. Têm pacientes que se apaixona por você na crise dele, ele se apaixona por você. Então quando ele escuta sua voz ele começa a se masturbar, só por que ouviu sua voz. [...] assim entre si, e entre mulher com mulher e homem com homem, na crise mesmo se você não tiver cuidado eles vão ter relações sexuais que depois eles vão se arrepender [...] (E20, PNS).

De acordo com Akiskal et al (2001 apud MORENO; MORENO: RATZKE, 2005 p.41); o aumento da libido é característico dos estados (episódios) maníacos psicóticos,

Enfatizaram a ativação psicomotora como central na mania, humor depressivo ou ansioso, além de eufórico ou irritável, ausência de crítica e quatro dos seguintes sintomas: aumento de energia, diminuição da necessidade de ajuda, grandiosidade, sociabilidade excessiva, aumento da libido, fuga de idéias e distratibilidade. (Grifos nossos).

Percebemos que a percepção dos profissionais a cerca da libido exacerbada no momento do surto é a única referência da sexualidade que eles têm do doente mental.

\section{Prática sexual encarada como sendo apenas um ato sexual e heterossexual}

A respeito da existência das práticas sexuais do doente mental na instituição psiquiátrica, a maioria dos entrevistados relaciona a prática sexual apenas como à prática heterossexual, negando outras possíveis expressões da sexualidade.

[...] Não existe prática sexual do paciente nessa instituição não, mesmo por que é assim, eles ficam separados e aqueles mais conscientes, tem os finais de semana deles, são casados tem os finais de semana deles e o resto fica tudo dividido, separado. (E2, PNM).

Como eu disse antes são separados, homens é de um lado e mulheres do outro aí quando tem uma coisa ou outra assim agente já separa, já toma logo uma atitude, não acontece não prática sexual. (E12, PNM).

Segundo Toniette (2006 apud HELLMANN, 2006) como mencionamos na revisão bibliográfica, a sexualidade condiz como um modo de bem-estar que inclui: um conjunto de valores, atitudes, papéis, práticas, características culturais e vínculo emocional, identidade sexual e de gênero 
(como a pessoa se identifica) logo a as práticas sexuais estão pautadas na subjetividade de cada indivíduo e não no modelo unicamente heterossexual.

\section{O Surto em forma de delírio como justificativo para a manifestação da sexualidade do Doente Mental}

Verificamos que uma porcentagem significativa dos entrevistados associou o estado de desvario do paciente como o único meio pelo qual ele expressa sua sexualidade.

[...] Quando a família se preocupa com a sexualidade do seu enfermo e se pergunta: 'Será que meu filho ta trepando com outro? Será que meu filho ta querendo namorar? Será que meu filho ta virando gay?”a preocupação é essa só, ai agente diz: não senhora é porquê ele ta em crise , só porquê ele está em crise mas vai passar [...] (E20, PNS).

Às vezes eles são muito picantes, às vezes eles falam muito, comentam muito, mas também muito pela confusão mental também né. Às vezes eu acho que eles falam muito, mas só quando eles estão muito confusos, depois que eles vão saindo do surto eles vão... Não falam tanto. Não acho que eles sejam promíscuos não. Acho que é só do surto mesmo (E13, PNM).

Ao analisar as entrevistas percebemos que os profissionais não enxergam o paciente enquanto sujeito desejante quando fora do surto, negando assim à sexualidade desses indivíduos. Segundo Miranda e Furegato (2004) a negação da sexualidade do doente mental integra-se com a noção de desvio, por ser indicativo de estigma, visto que as deformidades físicas e os problemas relacionados ao caráter da pessoa dão sustentação a esse quadro.

\section{A Negação da Sexualidade do Doente Mental}

Quando indagamos sobre o que as pessoas pensam a respeito da sexualidade do doente mental, constatamos que a grande maioria percebe que a sociedade de um modo geral encara de forma preconceituosa a sexualidade do portador de doença mental, seja através da negação, pois acreditam que a patologia deste indivíduo o define como um ser "assexuado", ou também através do abuso sexual, pois foi recorrente na fala deles também que muitas pessoas se aproveitam da condição de doente desse indivíduo, para cometer abusos sexuais.

Outro fator que identifica o preconceito das pessoas em relação à sexualidade do paciente é a repressão em relação a qualquer manifestação de desejo sexual por parte do doente, já que acreditam 
que essa revelação do anseio sexual seja "ilícita" ou descabida. Como pode ser conferido em alguns extratos de discurso:

Olha as pessoas de fora acha que eles não tem sexo, eu acho que elas pensam que eles são pessoas assexual. Por que muitas pessoas nem se interessam nem pelo doente mental em si, pela pessoa, imagine pela sexualidade deles [...] (E20, PNS).

Olhe... eu não sei por que tem pessoas que as vezes se aproveitam do doente mental, dele está passando por um sofrimento psíquico, as vezes até fazem sexo irresponsavelmente, engravidam as pacientes, agente tem diversos casos aqui de mulheres que tem os filhos que não sabem nem quem é o pai ,entendeu?, as vezes eles agem com essa irresponsabilidade e se aproveita daquele sofrimento psíquico pra praticar sexo, até pra pessoas que fora da crise elas não teriam aquele tipo de comportamento , não se permitiriam , mas durante a crise elas ficam mais permissivas ...aí as pessoas que tem ...vamos dizer ...que se sentem normais aproveitam desses momentos pra esse tipo de prática. (E3, PNS)

A partir dessas falas percebemos como afirma Miranda; Furegato (2004) já citado anteriormente, que a sexualidade do doente mental provoca no profissional, de saúde um posicionamento de afastamento e até negação da mesma. Assim para os autores a sexualidade destes é vista como um estigma, pois é enxergada como desviante, como uma fraqueza ou desvantagem.

\section{Considerações Finais}

Essa pesquisa de campo buscou compreender as concepções de profissionais que trabalham em instituição psiquiátrica acerca da sexualidade do doente mental. Verificamos que a manifestação da sexualidade do doente mental é vista de forma exacerbada, portanto, descontrolada, como o próprio doente. O discurso dos participantes é pautado no exagero, na falta de medida, e nas entrelinhas, a instituição, e os que fazem parte dela, buscam controlar o excesso para manter a ordem interna, para isto usam medicação e ainda permitem uma "bonificação" do final de semana livre da instituição.

A masturbação é associada à doença e a prática sexual controlada na instituição é a heterossexual. Enfim, as crenças dos profissionais acerca da sexualidade são pautadas na relação sexualidade - relação sexual.

A sexualidade é reduzida pelos profissionais apenas a um dos seus aspectos ou a uma de suas dimensões que é a prática sexual mais especificamente a prática heterossexual. A mesma é percebida exclusivamente nos momentos de crise e como algo patológico.

Por todos os resultados aqui apontados evidenciamos a negação e repressão da sexualidade do doente mental, e como comprovação dessa negação os próprios profissionais citam a intensa 
verbalização que o doente mental expressa, esta seria a única forma que lhes é permitida de exercer a sua sexualidade.

Acreditamos que as concepções que os profissionais carregam consigo a respeito da sexualidade dos doentes mentais influenciam diretamente na forma de ver e agir frente a esse sujeito. Para que se alcance a promoção da saúde mental desses indivíduos não se pode ignorar esse aspecto da sua subjetividade, do contrário será infrutífero o tratamento assistencial, pois o homem vai muito além da sua dimensão física e, portanto o tratamento deve transcendê-la.

\section{Referências}

ALTMAN, H. Orientação sexual nos parâmetros curriculares nacional. 2001. Disponível em: http://www.scielo.br/scielo.php?script=sci.Acesso em: 18 de out. 2006.

ALVES, R. F.; EULÁLIO, M. C. e BRITO, S. M. O. Representações sociais, via de acesso ao pensamento social sobre a saúde-doença. In: FERNANDES, A.; CARVALHO, M. R.; SOBRINHO, M. D. (Orgs.). Representações sociais e saúde: construindo novos diálogos. Campina Grande: EDUEP, 2004.

AMARANTE, P. (Coord.). Saúde Mental, políticas e instituições: programa de educação à distância. Rio de Janeiro: FIOTEC/FIOCRUZ, EAD. 3v. v.2, 2003.

ARAÚJO, J. C. Narcisismo e relação narcísica de objeto. 2002. Disponível em: http://br.geocities.com/jcdaraujo/narcisismo.html. Acesso em 08 de dez. 2006.

BALlONE, G. J. O que é Doença Mental? 2006. In. Psiqweb: Psiquiatria Geral Disponível em: http://gballone.sites.uol.com.br/voce/doen.html. Acesso em 07 nov. 2006

BARDIN, L. Análise de Conteúdo. 1977. Presses Universitaires de France, 1997.

CANGUILHEM, G. O normal e o patológico. Rio de Janeiro: Forense Universitária, 1982.

CANO, M. A. T; et al. Sexualidade Na adolescência: um estudo bibliográfico. Ribeirão Preto, 2000 Disponível em: http://www.scielo.br/scielo.php?script=sci. Acesso em: 20 de out. 2006. 
CHAGAS, A. T. R. $O$ Questionário na Pesquisa Científica. 2000. Disponível em: http://www.fecap.br/adm_online/art11/anival.htm. Acesso em 20 de out. 2006.

ENGEL, M. G. As fronteiras da 'anormalidade': psiquiatria e controle social, 1999. Disponível em: http://www.scielo.br/scielo.php?script=sci. Acesso em: 15 de nov. 2006

FOUCAULT, M. História da sexualidade I: a vontade de saber. 1985. Trad. Maria Tereza da Costa Albuquerque e J. A. Guilhon Albuquerque. 7. ed. Rio de Janeiro: Graal, 1985.

Os anormais. Curso no Collège de France (1974-1975). São Paulo: Martins Fontes, $2001 \mathrm{a}$.

FRAGA, M. N. O.; Construção da reforma psiquiátrica brasileira: questão sobre o modo de inserção da enfermagem. In: Congresso Brasileiro de Enfermagem, 45., 1994, Recife. Enfermagem na perspectiva de saúde com qualidade. Recife, 1994.

GASKELL, G. Entrevistas individuais e grupais. In: BAUER, M. W.; GASKELL, G._Pesquisa qualitativa com texto, imagem e som: um manual prático. Petrópolis: Vozes, 2002.

GEJER, D. O adolescente com deficiência mental e sua sexualidade. 2006. Disponível em: http://www.entreamigos.com.br/textos/sexualid/oadole.htm. Acesso em 28 de nov. 2006.

GIAMI, A.; A medicalização da sexualidade. Foucault e Lantéri-Laura: história da medicina ou história da sexualidade? 2005. Disponível em: http://www.scielo.br/scielo.php?script=sci. Acesso em 16 de nov. de 2006.

GIL, A. C. Como Elaborar Projetos de pesquisa. 2002. 4. ed. São Paulo: Atlas, 2002.

GONÇALVES, C. C. O grito das mulheres foi ouvido: A experiência do grupo de Saúde mental da Equipe Amarela do Bairro do Pedregal - Campina Grande, Pb. 2005. 118f. Dissertação (Mestrado em Saúde Coletiva) - Faculdade de Ciências Biológicas, Universidade Estadual da Paraíba, Campina Grande, 2005.

GRINGS, E. S.; MALLMANN, M. T. O uso de lista de discussão na capacitação continuada de $\begin{array}{lllllll}\text { professores para } & 0 & \text { uso das } & \text { NTICs. } & 2000 . & \text { Disponível }\end{array}$ 
em:http://www.abed.org.br/antiga/htdocs/paper_visem/eeiane_schlemmer_srings.htm. Acesso em 22 de out. 2006.

HELlMANN, G.; Sexualidade, corporalidade e espiritualidade. 2006. Disponível em: http://www.gehspace.com/sexualidade56a60.htm. Acesso em 07 de nov. 2006.

JACOBINA, P. V.; Saúde mental e direito: Um diálogo sobre reforma psiquiátrica e sistema penal. 2003. Disponível em: http://www.scielo.br/pdf/rlae/v10n2/10516.pdf. Acesso em 20 de out. 2006.

MIRANDA, F. A. N.; FUREGATO, A. R. F. Percepções da Sexualidade do Doente Mental pelo Enfermeiro. 2001. Disponível em: http://www.scielo.br/pdf/rlae/v10n2/10516.pdf. Acesso em 10 de out. 2006.

Representações sociais da atuação do enfermeiro psiquiátrico no cotidiano, 2004. Disponível em: http://www.mackenzie.com.br/universidade/psico/publicacao/. Acesso em: 12 de Dez. 2006.

MIRANDA, F. A. N.; ARDAIA, A. R.; ARAÚJO, K. L.; Cotidiano da enfermagem psiquiátrica no hospital geral: perspectiva dos profissionais da saúde. 2000. Disponível em: http://www.scielo.br/pdf/rlae/v10n2/10516.pdf. Acesso em 11 de nov. 2006.

MORENO, R. A.; MORENO, D. H.; RATZKE, R.; Diagnóstico, tratamento e prevenção da mania e da hipomania no transtorno bipolar. 2005. Disponível em: http://www.scielo.br/pdf/rpc/v32s1/24411.pdf. Acesso em: 14de dez. 2006.

PRO PESQUISA. Metodologias e conceitos de pesquisa. 2006. Disponível em: http://www.propesquisa.com.br/welcome.phtml?sec_cod=90. Acesso em 22 de out. 2006.

PASSOS, I. C. F.; BEATO, M. S. F. Concepções e práticas sociais em torno da loucura: alcance e atualidade da história da loucura de Foucault para investigações etnográficas. 2003 Disponível em: http://www.scielo.br/scielo.php?script=sci. Acesso em 28 de nov. 2006.

PELBART, P. P.; Da clausura do fora ao fora da clausura. Rio de Janeiro: Graal, 1989. 
SANTO, J. M. R. Freud e a psicanálise: uma ligação indissolúvel. 2002. Disponível em: http://www.centrorefeducacional.pro.br/freudpsi.htm. Acesso em 07 de nov. 2006.

SILVEIRA, L. C.; BRAGA, V. A. B.; Acerca do conceito de loucura e seus reflexos na assistência de saúde. 2002. Disponível em: http://www.scielo.br/scielo.php?script=sci. Acesso em 20 de nov. 2006.

SOUZA, J. F. Gênero e sexualidade nas pedagogias culturais: implicações para a educação infantil. 2001. Disponível em: http://www.ced.ufsc.br/ nee0a6/SOUZA.pdf Acesso em 06 de out. 2006.

TORRE, E. H. G.; AMARANTE, P. Protagonismo e subjetividade; a construção coletiva no campo da saúde mental. 2001. Disponível em http://www.scielo.br/scielo.php?script=sci. Acesso em 03 de out. 2006.

VEnAnCIO, A. T A. Doença Mental, Raça e Sexualidade nas Teorias Psiquiátricas de Juliano Moreira. 2005. Disponível em: http://www.scielo.br/scielo. php?script=sci. Acesso em 28 set. 2006

Como citar este artigo (Formato ISO):

ALENCAR, A.V; EUlÁLIO, M.C.; GARCIA, J.S.B.L. Concepções dos Profissionais de Saúde acerca da sexualidade do portador de Doença Mental. Id on Line Revista de Psicologia, Novembro de 2013, vol.1, n.21, p. 64-84. ISSN 1981-1189. 